\title{
Awareness, handling and storage factors associated with aflatoxin contamination in spices marketed in Dar es Salaam, Tanzania
}

\author{
S.S. Fundikira ${ }^{1 *}$, S. De Saeger ${ }^{2,3,4}$, M.E. Kimanya ${ }^{4,5}$ and J.K. Mugula ${ }^{1}$ \\ ${ }^{1}$ Department of Food Technology, Nutrition and Consumer Sciences, Sokoine University of Agriculture, P.O. Box 3006, \\ Morogoro, Tanzania; ${ }^{2}$ Centre of Excellence in Mycotoxicology and Public Health, Department of Bio-analysis, Ghent \\ University, Ghent 9000, Belgium; ${ }^{3}$ Department of Biotechnology and Food Technology, Faculty of Science, University of \\ Johannesburg, Doornfontein Campus, Gauteng, South Africa; ${ }^{4}$ MYTOX-SOUTH, Ghent, Belgium; ${ }^{5}$ School of Life Sciences \\ and Bio-Engineering, the Nelson Mandela African Institution of Science and Technology (NM-AIST), P.O. Box 447, Arusha, \\ Tanzania; sambwe.fundikira@sua.ac.tz; sambwef@gmail.com
}

Received: 5 June 2020 / Accepted: 6 September 2020

(c) 2020 Wageningen Academic Publishers

OPEN ACCESS CC) (i) (2) RESEARCH ARTICLE

\begin{abstract}
A structured questionnaire was used to collect information of awareness, knowledge and practices associated with aflatoxin contamination in spices from 30 retailers in Dar es Salaam. Aflatoxin contamination in spices was analysed using high performance liquid chromatography (HPLC) with fluorescence detection using post column derivatization. Data were statistically analysed to assess factors associated with aflatoxin contamination in the study community. $58 \%$ of the spice samples were contaminated and the mean of total aflatoxin level in ginger, cinnamon, cloves and cardamom was $2.67,2.88,2.79$ and $2.26 \mu \mathrm{g} / \mathrm{kg}$, respectively. Significant majorities (96.7\%) of the respondents were not aware of aflatoxin contamination of spices during storage and its effect on health. Farmers as source where spices were procured and storage time of more than 14 days showed significant association with aflatoxin contamination with odds ratio $(\mathrm{OR})=0.178,95 \%$ confidence interval $(\mathrm{CI})=0.061-0.525, P=0.002$ and $\mathrm{OR}=3.608,95 \% \mathrm{CI}=1.099$ $11.845, P=0.034$, respectively. This is the first report of aflatoxin contamination in spices consumed in Tanzania. The levels of contamination are high and associated spices that was procured from farmers and long storage time. This calls for urgent raising of awareness and knowledge on good management practices for prevention of aflatoxin contamination of spices in Tanzania.
\end{abstract}

Keywords: mycotoxins, food safety, handling, spices, Tanzania

\section{Introduction}

Mycotoxins are biologically active secondary metabolites produced by a variety of moulds, such as Aspergillus, Penicillium, and Fusarium (Cammilleri et al., 2019). They can grow in a wide variety of foods including cereal grains, nuts, oilseeds, fruits, dried fruits, vegetables, cocoa and coffee beans, wine, beer, as well as herbs and spices. Mycotoxins can also be found in animal-derived food, such as meat, eggs, milk, and milk derivatives if the animals were fed contaminated feed (Bryden, 2012; Marin, 2013). It has been reported that $5-10 \%$ of agricultural products in the world are contaminated by moulds to the extent that they cannot be consumed by animals and humans (Tosun et al., 2013).
There are currently more than 400 known mycotoxins worldwide. However, five groups of mycotoxins are considered potentially dangerous or of economic importance, including aflatoxins, ochratoxins, fumonisins, citrinin, zearalenone and trichothecenes (Ismaiel and Papenbrock, 2015). Aflatoxins are one of the highly toxic secondary metabolites derived from polyketides produced by mould species, such as Aspergillus flavus, Aspergillus parasiticus, and Aspergillus nomius (Filazi and Sireli, 2013; Omar, 2013). The moulds produce four main types of aflatoxin: aflatoxin $B_{1}, B_{2}, G_{1}$ and $G_{2}\left(A_{1 F}, A_{1} B_{2}\right.$, $\mathrm{AFG}_{1}$, and $\mathrm{AFG}_{2}$ ). $\mathrm{AFB}_{1}$, the most carcinogenic mycotoxin, is typically produced in higher quantities than the other aflatoxin forms. They are found in various cereals, oilseeds, spices, and nuts (Iqbal et al., 2012; Reddy, 2010). 
Aflatoxins cause a number of adverse health effects in both animals and humans, resulting in economic loss and undesirable trade barrier for both raw materials and consumable products. They are highly carcinogenic, hepatotoxic, mutagenic, teratogenic, and are correlated with immunosuppression, reduced nutrients absorption and stunting of infants, and are fatal in high doses (Lippolis et al., 2017; Lutfullah and Hussain, 2012). In the past few decades incidences of aflatoxicosis have been reported within sub-Saharan Africa, including the 2004 event in Kenya (Lewis et al., 2005) and the 2016 aflatoxin outbreaks in Chemba and Kiteto districts of Tanzania (Kamala et al, 2018; WHO, 2017). Chronic exposure due to low levels of contamination consumed regularly, increases liver cancer risks and can suppress the immune system, particularly for the population with hepatitis B virus (HBV), while very high levels of aflatoxin can cause poisoning and even death to humans (Makun et al., 2011). The International Agency for Research on Cancer (IARC) classified naturally occurring mixes of aflatoxins as Group 1 human carcinogens (IARC, 2002).

The extent of food and feed contamination with aflatoxin vary with geographical location, agricultural and agronomic practice, and the susceptibility of food contamination with aflatoxins during pre-harvest, storage and processing period (Arapcheska et al., 2015). Aflatoxin contamination of crops including spices usually occurs when crops are not properly dried or when stored in a highly humid environment (Asghar et al., 2016; Thanushree et al., 2019). Many studies have shown that factors that are associated with aflatoxin contamination in developing countries include poor preand post-harvest handling practices (Kamala et al., 2016), low awareness about aflatoxins and the health effects associated with aflatoxin contamination (Unnevehr et al., 2013) and other inefficient regulatory enforcement and educational programs (WHO, 2006).

Spices are increasingly popular in the Tanzania market. Their uses are not limited to food but extend to industrial and medicinal uses. However, these commodities are susceptible to aflatoxin contamination due to the environmental conditions they are exposed to throughout the value chain. Many studies have reported on the factors associated with aflatoxin contamination including pre- and post-harvest handling of crops, low levels of awareness and knowledge of consumers and producers/handlers of crops, educational and regulatory programs (Ayo et al., 2018; Kamala et al., 2016; Magembe et al., 2017; Monyo et al, 2010; Ngoma et al., 2017; WHO, 2006). However, these studies are mainly concentrated on common staple crops, such as maize, groundnut and animal feeds. Limited studies have reported on the occurrence or the influence of awareness and knowledge of aflatoxin contamination in spices traded in Tanzania. Therefore, the objectives of this study were to analyse aflatoxin contamination in spices from
Tanzanian markets and to assess the awareness, handling and storage practices of retailers dealing with marketed spices and how these factors enhance or minimise aflatoxin contamination in the commodity.

\section{Materials and methods}

\section{Study design and study population}

A cross sectional descriptive study was carried out between December 2017 and January 2018 in three markets; one located in each of the districts of Ilala, Kinondoni and Temeke in Dar es Salaam region. The region was selected for this study because it has the highest urbanised population which provides a market for agricultural produces (including spices) from all the other regions of the country. The markets of Ilala, Kinondoni and Temeke were selected for this study because of the bigger size, easier to access location and more affordable prices compared to other markets in the region.

The study population was all the retailers of spices in the study markets. Spice retailers serve as the integral link between farmers, wholesalers, transporters and consumers in the spice value chain. Additionally, these people were more likely to make informed decisions and respond to the study questions, responsively as they interact with farmers and consumers from different regions.

\section{Sample size estimation}

Since the exact population of spice retailers was unknown, the sample size was estimated using the Kothari equation (Kothari and Garg, 2014):

$\mathrm{n}=\mathrm{z}^{2} \mathrm{P} \frac{(1-\mathrm{P})}{\mathrm{e}^{2}}$

where $\mathrm{n}=$ sample size, $\mathrm{Z}=$ standard variate at a given confidence level, for this study a $95 \%$ confidence level = 1.96 at and $\mathrm{e}=$ acceptable error (the precision/ estimation error) set at $8 \%(0.08)$ for this study. Thus, the sample size of the study was $n=1.96^{2} \times 0.05(1-0.05) / 0.08^{2}=30$ retailers.

\section{Sampling techniques and procedures}

Probability sampling technique was employed. This technique was considered to be fit for the study because it gives equal chance to all the study respondents in the population to be selected and thus eliminating the possibility of bias in selection. It also provides a basis for the application of statistical theory of results. The study respondents were randomly selected in their respective markets through simple random sampling. Four samples of different commonly consumed spices (cinnamon, 
cloves, ginger and cardamom) were collected from each respondent after conducting the interview in the three districts, between December 2017 and January 2018. More samples were taken from Ilala market compared to Kinondoni or Temeke markets since most of the big markets/retailers were found in this market hence improve precision by taking into consideration the heterogeneous distribution of aflatoxins in the spices. A total of 120 (32 from Kinondoni, 36 from Temeke and 52 from Ilala) dried and powdered samples of cinnamon, ginger, clove and cardamom were collected in clean polythene bags from the 30 randomly selected retailers. Numbers of the different spices collected from each of the districts are shown in Table 1. The samples were coded, transported to the Tanzania Bureau of Standards (TBS) food laboratory and stored at $4{ }^{\circ} \mathrm{C}$ until the time of aflatoxin analysis.

\section{Data collection tools}

The data was collected using quantitative methods. A questionnaire (with closed and open-ended questions) was administered to the respondents who had verbally consented to participate in the study. This questionnaire was originally prepared in English and translated into Kiswahili. The questionnaire consisted of thirty questions that attempted to capture information on awareness, knowledge, handling and storage practices the spice retailers. It was pretested on a random sample of 10 spice retailer at Sinza Africa Sana Market to provide a clear indication on the response and relevance of the questions to the study objectives.

\section{Aflatoxin analysis}

Spice samples were analysed for $\mathrm{AFB}_{1}, \mathrm{AFB}_{2}, \mathrm{AFG}_{1}$, and $\mathrm{AFG}_{2}$, using HPLC with fluorescence detection after post column derivatization (achieved by Photochemical Reactor $\mathrm{UVE}^{\mathrm{m}}$; LCTech GmbH, Dorfen, Germany) as described in ISO 16050 with some modification.

\section{Chemicals and standards}

The chemicals and reagents used in sample preparation were of chromatography grade. These included acetonitrile, methanol and water, all of HPLC grade (Fisher Chemical,

Table 1. Number of samples collected from each municipality market.

$\begin{array}{llllll} & \text { Cinnamon } & \text { Ginger } & \text { Clove } & \text { Cardamom } & \text { Total } \\ \text { Kinondoni } & 8 & 8 & 8 & 8 & 32 \\ \text { Temeke } & 9 & 9 & 9 & 9 & 36 \\ \text { Ilala } & 13 & 13 & 13 & 13 & 52 \\ \text { Total } & 30 & 30 & 30 & 30 & 120\end{array}$

Loughborough, UK). BIOPURE ${ }^{\text {mi }}$ Mix 9 aflatoxins standard $\left(\mathrm{AFB}_{1}, \mathrm{AFB}_{2}, \mathrm{AFG}_{1}\right.$ and $\left.\mathrm{AFG}_{2}\right) 1 \mathrm{mg} / \mathrm{kg}$ each in acetonitrile was used as stock standard from Romer Labs GmbH (Tulln, Austria).

\section{Extraction of samples}

Cinnamon, clove, cardamom and ginger samples were ground separately to obtain a homogenous flour mixture and then sub-divided to obtain representative subsamples for analysis. Each ground spice sample was placed into an Erlenmeyer flask and weighed using the calibrated analytical balance to $25 \pm 0.1 \mathrm{~g}$. Using a measuring cylinder, $100 \mathrm{ml}$ of methanol:water (70:30, v/v) as extraction solvent was added to the $250 \mathrm{ml}$ Erlenmeyer flask containing the sample. The flask was covered with aluminium foil and placed on the gyratory shaker (Stuart ${ }^{\oplus}$ Orbital Shaker SSL1; Cole-Parmer LLC, Vernon Hills, IL, USA) at $250 \mathrm{rpm} / 30 \mathrm{~min}$, then using a Whatman No. 1 filter paper (Whatman, Maidstone, UK), the extract was filtered into a $250 \mathrm{ml}$ Erlenmeyer flask according to the procedure described in the ISO 16050.

\section{Dilution stage}

The sample extract $(4 \mathrm{ml})$ was transferred to a $15 \mathrm{ml}$ centrifuge tube, followed by addition of $8 \mathrm{ml}$ of distilled water. Then, the mixture was vortexed (Talboys ${ }^{\oplus}$ Hvy Dty Vortex, Troemner LLC, Thorofare, NJ, USA) for $1 \mathrm{~min}$ to get a homogeneous mixture.

\section{Isolation and clean-up of aflatoxins}

The diluted extract was loaded onto and allowed to pass through Solid Phase Extraction (SPE) Aflastar ${ }^{\mathrm{mm}}$ immunoaffinity columns (Romer Labs $\mathrm{GmbH}$ ) and the sample loaded columns were rinsed twice with $10 \mathrm{ml}$ of HPLC grade water. The adsorbed aflatoxins were eluted with $1 \mathrm{ml}$ of HPLC grade methanol and the eluents were collected in vials. Finally, pressure was slightly applied on top of the column to remove any remaining liquid. A volume of $0.3 \mathrm{ml}$ of the eluate was mixed with $0.6 \mathrm{ml}$ of water and $0.1 \mathrm{ml}$ of acetonitrile and the mixture was vortexed for $30 \mathrm{~s}$.

\section{HPLC system}

After extraction, dilution, cleaning and elution and post-column derivatization, the extracts were analysed using HPLC with fluorescence detector (FLD) (Model Agilent ChemStation technology, series 1200; Agilent, Santa Clara, CA, USA). The mobile phase contained water:methanol:acetonitrile $(60: 30: 10, \mathrm{v} / \mathrm{v} / \mathrm{v})$. The separation of aflatoxins $\left(\mathrm{AFB}_{1}, \mathrm{AFB}_{2}, \mathrm{AFG}_{1}\right.$ and $\left.\mathrm{AFG}_{2}\right)$ was performed on the Eclipse XDB- C18 $(5 \mu \mathrm{m}, 4.6 \times 150 \mathrm{~mm})$ column from Agilent at a temperature of $30^{\circ} \mathrm{C}$ and a flow rate of $1.2 \mathrm{ml} / \mathrm{min}$. The injection volume was $50 \mu \mathrm{l}$ for both standard solution and sample extracts. After separation, 
$\mathrm{AFG}_{1}$ and $\mathrm{AFB}_{1}$ were derivatised by photochemical reactor $\mathrm{UVE}^{\mathrm{ra}}(\mathrm{LCTech} \mathrm{GmbH})$ to allow their detection with FLD at an emission wavelength of $465 \mathrm{~nm}$ and an excitation wavelength of $360 \mathrm{~nm}$.

Determination of recoveries, limit of detection and limit of quantification of the HPLC method

The accuracy of the method was determined by determining recovery of aflatoxins by calculating the percentage recovery of aflatoxin spiked blank spice samples. The limit of detection (LOD) and limit of quantification (LOQ) of the HPLC method for $\mathrm{AFB}_{1}, \mathrm{AFB}_{2}, \mathrm{AFG}_{1}$ and $\mathrm{AFG}_{2}$ were calculated using Equations 2 and 3, respectively:

LOD $=$ Mean of the lowest concentration $+3 S D$

LOQ $=$ Mean of the lowest concentration +10 SD

where SD = standard deviation of the lowest concentration.

\section{Statistical analysis}

The data was analysed using Statistical Package for Social Sciences (IBM SPSS ${ }^{\oplus}$ Version 18, Armonk, NY, USA). The data was coded appropriately and fed into SPSS version 18 to determine the frequencies. Also logistic regression (multivariate) analysis was used to describe and determine the relationship or association between the independent variables and aflatoxin contamination of spices. Odds ratios (OR) determined associations between aflatoxin contamination and the respondents' characteristics (independent variables) at 95\% confidence interval (CI). P-values that were less than 0.05 were considered statistically significant. Data cleaning was primarily done to ensure there was no information missing. The analysis involved descriptive statistics to describe the sample population, socio demographic, awareness, handling and storage practices, in frequency tables. The chi square test was used for showing association between study independent variables such as socio demographic, awareness, handling and storage practices; and dependent variable (aflatoxin contamination) during statistical analysis.

Data from the laboratory analysis of aflatoxins was also analysed using Genstat Version 14.2, VSN International Ltd. (Hemel Hempstead, UK). One-way analysis of variance (ANOVA) was used to test significance of the difference in the aflatoxin levels amongst the types of marketed spices and study districts. The differences between means in $\mathrm{AFB}_{1}$, $\mathrm{AFB}_{2}, \mathrm{AFG}_{1}, \mathrm{AFG}_{2}$ and total aflatoxins were determined using Duncan's multiple range tests.

\section{Results}

\section{Recovery, limit of detection and limit of quantification of aflatoxins}

The recoveries of all aflatoxins were greater than $70 \%(71.5$ to $73.6 \%$ ) (Table 2) indicating the suitability and good performance of the approved aflatoxin extraction protocol and quantification (Shah et al., 2000). LOD and LOQ for $\mathrm{AFB}_{1}, \mathrm{AFB}_{2}, \mathrm{AFG}_{1}$, and $\mathrm{AFG}_{2}$ ranged from 0.13-0.16 $(\mu \mathrm{g} / \mathrm{kg})$ and $0.16-0.29(\mu \mathrm{g} / \mathrm{kg})$, respectively.

\section{Demographic characteristics of the respondents}

The majorities of the study respondents (Table 3 ) were male, aged between 27 to 35 years and have completed primary education. The average business experience of the respondents was $8.7 \pm 7.5$ years, of which $50.0 \%$ of the respondents reported to have less than 5 years of business experience in dealing with spices.

\section{Aflatoxin contamination in spices}

Out of the 120 spice samples collected, 69 (57.5\%) were contaminated with aflatoxins, out of which 49 samples (40.8\%) were contaminated with AFB $_{1}$ (Table 4). The total aflatoxin contamination ranged from $0.13-11.2 \mu \mathrm{g} / \mathrm{kg}$ in cinnamon, $0.55-9.66 \mu \mathrm{g} / \mathrm{kg}$ in ginger, $0.16-11.2 \mu \mathrm{g} / \mathrm{kg}$ in cloves and $0.23-11.9 \mu \mathrm{g} / \mathrm{kg}$ in cardamom. Cloves show high prevalence with $\mathrm{AFB}_{1}$ and total aflatoxin with 63.3 and $70.0 \%$, respectively. From the samples that were found to be contaminated with aflatoxins, there were spices that exceeded the EU regulatory limits for $\mathrm{AFB}_{1}(5 \mu \mathrm{g} / \mathrm{kg})$ and

\section{Table 2. Recovery of aflatoxins from spiked spice samples.}

\begin{tabular}{|c|c|c|c|}
\hline $\begin{array}{l}\text { Spiked } \\
\text { concentration } \\
(\mu \mathrm{g} / \mathrm{kg})\end{array}$ & Aflatoxins ${ }^{1}$ & $\begin{array}{l}\text { Detected } \\
\text { concentration } \\
(\mu \mathrm{g} / \mathrm{kg})\end{array}$ & $\%$ Recovery \\
\hline \multirow[t]{4}{*}{1.00} & $\mathrm{AFB}_{1}$ & 0.70 & 70.3 \\
\hline & $\mathrm{AFB}_{2}$ & 0.71 & 70.6 \\
\hline & $\mathrm{AFG}_{1}$ & 0.71 & 71.1 \\
\hline & $\mathrm{AFG}_{2}$ & 0.71 & 70.9 \\
\hline \multirow[t]{4}{*}{3.00} & $\mathrm{AFB}_{1}$ & 2.18 & 72.8 \\
\hline & $\mathrm{AFB}_{2}$ & 2.14 & 71.2 \\
\hline & $\mathrm{AFG}_{1}$ & 2.13 & 71.0 \\
\hline & $\mathrm{AFG}_{2}$ & 2.14 & 71.4 \\
\hline \multirow[t]{4}{*}{5.00} & $\mathrm{AFB}_{1}$ & 3.69 & 73.6 \\
\hline & $\mathrm{AFB}_{2}$ & 3.67 & 73.4 \\
\hline & $\mathrm{AFG}_{1}$ & 3.57 & 71.5 \\
\hline & $\mathrm{AFG}_{2}$ & 3.64 & 72.8 \\
\hline
\end{tabular}


Table 3. Demographic characteristics of study respondents.

\begin{tabular}{|c|c|c|}
\hline Description & $\begin{array}{l}\text { Frequency } \\
(n=30)\end{array}$ & $\begin{array}{l}\text { Percentage } \\
\%\end{array}$ \\
\hline \multicolumn{3}{|l|}{ District } \\
\hline Kinondoni & 8 & 26.7 \\
\hline Ilala & 13 & 43.3 \\
\hline Temeke & 9 & 30.0 \\
\hline \multicolumn{3}{|l|}{ Sex } \\
\hline Male & 25 & 83.3 \\
\hline Female & 5 & 16.7 \\
\hline \multicolumn{3}{|l|}{ Age categories } \\
\hline $18-26$ & 6 & 20.0 \\
\hline $27-35$ & 12 & 40.0 \\
\hline $36-44$ & 8 & 26.7 \\
\hline 45 and above & 4 & 13.3 \\
\hline \multicolumn{3}{|l|}{ Level of education } \\
\hline Less than primary education & 1 & 3.3 \\
\hline Primary education & 15 & 50.0 \\
\hline Lower than ordinary secondary level & 3 & 10.0 \\
\hline Ordinary secondary level & 10 & 33.3 \\
\hline Post-secondary/tertiary & 1 & 3.3 \\
\hline \multicolumn{3}{|l|}{ Marital status } \\
\hline Never married & 10 & 33.3 \\
\hline Married & 20 & 66.7 \\
\hline \multicolumn{3}{|l|}{ Business years } \\
\hline Up to 5 years & 15 & 50.0 \\
\hline $6-10$ years & 8 & 26.7 \\
\hline More than 10 years & 7 & 23.3 \\
\hline
\end{tabular}

total aflatoxin $(10 \mu \mathrm{g} / \mathrm{kg})$ with highest concentrations of $11.2 \mu \mathrm{g} / \mathrm{kg}$ and $11.9 \mu \mathrm{g} / \mathrm{kg}$, respectively. $71 \%$ of all contaminated samples were contaminated with $\mathrm{AFB}_{1}$ $(0.15-11.2 \mu \mathrm{g} / \mathrm{kg})$.

\section{Handling and storage practices}

Table 5 shows that the majority of the respondents did not further dry their spices after receipt. Sorting of spices was done by taking different aspects of the spices into consideration, like insect damage/infestation, mould and other physical properties. The majority of the spice handlers discarded spices that appeared to be spoilt after sorting, and packed their spices prior to sale.

\section{Knowledge and awareness of spoilage and aflatoxin contamination}

Table 6 shows that all the retailers could correctly identify well dried spices, a significant majority could identify spoiled spices and almost none of them were aware of aflatoxin contamination in spices.

\section{Factors associated with aflatoxin contamination in spices}

\section{Result of logistic regression analysis}

The OR of spices collected from respondents being contaminated with aflatoxins varied significantly with age of the retailers, where spices were purchased from and the storage length of the spices (Table 7). The age of

Table 4. Occurrence of aflatoxins in spices.

\begin{tabular}{|c|c|c|c|c|c|}
\hline Spice & Aflatoxin & $\begin{array}{l}\text { Positive samples }{ }^{1} \text {, } \\
\text { n (\%) }\end{array}$ & $\begin{array}{l}\text { Samples exceeding } \\
\text { EU limits }{ }^{2}, n(\%)\end{array}$ & Median $(\mu \mathrm{g} / \mathrm{kg})$ & Range $(\mu \mathrm{g} / \mathrm{kg})$ \\
\hline \multirow[t]{2}{*}{ Cinnamon } & Aflatoxin $B_{1}$ & $8(26.7)$ & $1(12.5)$ & 1.39 & $0.39-11.2$ \\
\hline & Total aflatoxins & $13(43.3)$ & $1(7.7)$ & 2.63 & $0.13-11.2$ \\
\hline \multirow[t]{2}{*}{ Cloves } & Aflatoxin $\mathrm{B}_{1}$ & $19(63.3)$ & $1(5.3)$ & 0.87 & $0.15-11.2$ \\
\hline & Total aflatoxins & $21(70.0)$ & $1(4.8)$ & 1.61 & $0.16-11.2$ \\
\hline \multirow[t]{2}{*}{ Ginger } & Aflatoxin $B_{1}$ & $12(40.0)$ & $2(16.7)$ & 0.63 & $0.18-9.66$ \\
\hline & Total aflatoxins & $17(56.7)$ & $0(0.0)$ & 1.43 & $0.55-9.66$ \\
\hline \multirow[t]{2}{*}{ Cardamom } & Aflatoxin $\mathrm{B}_{1}$ & $10(33.3)$ & $2(20.0)$ & 1.17 & $0.23-7.20$ \\
\hline & Total aflatoxins & $18(60.0)$ & $2(11.1)$ & 1.90 & $0.23-11.9$ \\
\hline \multirow[t]{2}{*}{ Overall } & Aflatoxin $B_{1}$ & $49(40.8)$ & $6(5.0)$ & 0.83 & $0.15-11.2$ \\
\hline & Total aflatoxins & $69(57.5)$ & $4(3.3)$ & 1.39 & $0.13-11.9$ \\
\hline
\end{tabular}

\footnotetext{
${ }^{1}$ Positive samples are all analysed samples with value > limit of detection. $\mathrm{n}$ is the total number of analysed samples for each spice.

${ }^{2}$ EU regulatory limits for aflatoxin $B_{1}(5.0 \mu \mathrm{g} / \mathrm{kg})$ and total aflatoxin $(10.0 \mu \mathrm{g} / \mathrm{kg})$.
} 
Table 5. Variation of sources, quantities purchased at a time and handling practices for the samples.

\begin{tabular}{|c|c|c|c|}
\hline Variable & Description & $\begin{array}{l}\text { Frequency } \\
(n=30)\end{array}$ & $\begin{array}{l}\text { Percentage } \\
\%\end{array}$ \\
\hline \multirow[t]{3}{*}{ Source of spices } & farmers & 12 & 40.0 \\
\hline & outlets & 13 & 43.3 \\
\hline & others & 5 & 16.7 \\
\hline \multirow{5}{*}{$\begin{array}{l}\text { Quantity of spices } \\
\text { purchased }(\mathrm{kg})\end{array}$} & less than 200 & 15 & 50.0 \\
\hline & $200-400$ & 2 & 6.6 \\
\hline & $400-600$ & 5 & 16.7 \\
\hline & more than 600 & 3 & 10.0 \\
\hline & depend on demand & 5 & 16.7 \\
\hline \multirow[t]{2}{*}{ Sorting of spices } & yes & 23 & 76.7 \\
\hline & no & 7 & 23.3 \\
\hline \multirow[t]{3}{*}{ Criteria for sorting } & physical properties & 14 & 46.7 \\
\hline & insects/moulds & 9 & 30.0 \\
\hline & no sorting done & 7 & 23.3 \\
\hline \multirow[t]{2}{*}{ Further drying } & yes & 11 & 36.7 \\
\hline & no & 19 & 63.3 \\
\hline \multirow[t]{3}{*}{ Storage length (days) } & less than 7 days & 19 & 63.3 \\
\hline & $7-14$ days & 8 & 26.7 \\
\hline & more $>14$ days & 3 & 10.0 \\
\hline \multirow[t]{2}{*}{ Further packing } & yes & 29 & 96.7 \\
\hline & no & 1 & 3.3 \\
\hline \multirow{5}{*}{$\begin{array}{l}\text { Fate of sorted out } \\
\text { spices }\end{array}$} & thrown away & 19 & 63.3 \\
\hline & recall to supplier & 2 & 6.7 \\
\hline & re-drying and sell & 1 & 3.3 \\
\hline & store and mill & 1 & 3.3 \\
\hline & others & 7 & 23.4 \\
\hline
\end{tabular}

respondents $(\mathrm{OR}=0.326,95 \% \mathrm{CI}=0.113-0.940, P=0.038)$ was weakly associated with aflatoxin contamination of spices collected. The source where the spices were purchased from
$(\mathrm{OR}=0.178,95 \% \mathrm{CI}=0.061-0.525, P=0.002)$ was also weakly associated with aflatoxin contamination of spices. The storage length $(\mathrm{OR}=3.608,95 \% \mathrm{CI}=1.099-11.845, P=0.034)$ was strongly associated with aflatoxin contamination of spices.

\section{Practices associated with presence of aflatoxins in spices}

Table 8 shows that the prevalence of aflatoxin contamination of spices was significantly higher among respondents who did not complete primary school education, and who did not attend any training related to food handling and storage. The prevalence of aflatoxin contamination was high and significantly associated with respondents who purchased spices from farmers.

\section{Discussion}

\section{Handling and storage practices}

The responses indicated that most of the respondents (63.3\%) did not further dry their spices after receipt. Furthermore, the majority of the respondents (76.7\%) sorted the spices after receipt. About $47 \%$ of the participants (46.7\%) acknowledged considering physical aspects during sorting, such as inspecting the overall physical appearance, discoloration and cleanliness as compared to others (30.0\%) who considered insect infestation and mouldiness of the spices. It has been reported that physical sorting is also another effective measure in a reduction - as high as 40$80 \%$ - of aflatoxins (Bullerman and Bianchini, 2007). It was also observed that spices stored for more than 14 days were more likely (three times the odds) to be contaminated with aflatoxins compared to those stored for less than 7 days and between 7 and 14 days. This finding is similar to that reported by Adekoya et al. (2017) in a study of the relationship between storage and marketing practices and

Table 6. Levels of knowledge or awareness of aflatoxin contamination among retailers.

\begin{tabular}{lll} 
Variable & Number $(\mathbf{n})^{1}$ & Affirmative yes (\%) \\
& & 83.3 \\
Know causes of spoilage & 25 & 93.3 \\
Can identify spoiled spices & 28 & 100.0 \\
Can identify well dried spices & 30 & 3.3 \\
Had heard of aflatoxins & 1 & 0 \\
Had heard of toxins caused by mould & 0 & 3.3 \\
Aware of aflatoxin contamination during storage & 1 & 3.3 \\
Aware of aflatoxin contamination in spices & 1 & 0 \\
Aware of the effects of aflatoxins in humans & 0 & 3.3 \\
Aware of the effects of aflatoxins in animals & 0 & 1 \\
Attended any training related to food handling and storage & & 0 \\
\hline The number of respondents who gave an affirmation to the question. & &
\end{tabular}


Table 7. Multivariate analysis results: Relationship between demographic characteristics, awareness, knowledge or handling practices and aflatoxin contamination of spices.

\begin{tabular}{|c|c|c|c|c|c|}
\hline & \multirow[t]{2}{*}{ Factor } & \multirow[t]{2}{*}{ Odds ratio } & \multicolumn{2}{|c|}{$95 \%$ confidence interval } & \multirow[t]{2}{*}{$P$-value ${ }^{1}$} \\
\hline & & & Lower limit & Upper limit & \\
\hline Age group & $36-44$ years & 0.326 & 0.113 & 0.940 & $0.038^{*}$ \\
\hline Being a female & & 0.907 & 0.099 & 8.305 & 0.931 \\
\hline District & Temeke & 1.071 & 0.348 & 3.302 & 0.905 \\
\hline Education level & completed ordinary education & 0.465 & 0.156 & 1.385 & 0.169 \\
\hline Marital status & never married & 1.052 & 0.117 & 9.484 & 0.964 \\
\hline Sourced from farmers & farmers & 0.178 & 0.061 & 0.525 & $0.002^{*}$ \\
\hline Can identify spoiled spices & & 0.789 & 0.005 & 125.8 & 0.927 \\
\hline Know causes of spoilage in spices & & 0.142 & 0.005 & 3.953 & 0.250 \\
\hline Further drying of spices & & 0.776 & 0.196 & 3.077 & 0.718 \\
\hline Sorting of spices & & 4.971 & 0.231 & 107.2 & 0.306 \\
\hline Criteria for sorting & no sorting done & 0.374 & 0.076 & 1.831 & 0.225 \\
\hline Storage & $>14$ days storage & 3.608 & 1.099 & 11.85 & $0.034^{*}$ \\
\hline Attended any training related to food & & 0.000 & 0.000 & 0.000 & 0.999 \\
\hline Having heard of the word aflatoxin before & & 1.231 & 0.048 & 31.77 & 0.900 \\
\hline Business years' experience & more $>10$ years & 2.085 & 0.616 & 7.055 & 0.238 \\
\hline Packaged spices & & 0.265 & 0.007 & 10.18 & 0.476 \\
\hline What form do you pack the spices & nylon bags & 0.265 & 0.007 & 10.18 & 0.476 \\
\hline
\end{tabular}

mycotoxin contamination. Likewise, Sasamalo et al. (2018) observed the increase in aflatoxin levels with extended storage duration of stored maize in central Tanzania.

\section{Awareness and knowledge on aflatoxin contamination}

A significant majority (96.7\%) of the respondents had never heard of aflatoxins before and also was not aware of aflatoxin contamination of spices during storage. This is also supported by the low percentage $(3.3 \%)$ of traders that had attended training on food handling and storage. Spice retailers' unawareness on aflatoxins in this study could be a major contributing factor to aflatoxin contamination, and hence a danger to public health. The low aflatoxin awareness is similar to observations reported among parents of young children in central Tanzania, where only $3.6 \%$ of the parents confirmed to have heard of aflatoxins (Ngoma et al., 2017). In contrast, the low awareness rate observed in this study was significantly lower than that reported by Ayo et al. (2018) for livestock farmers (28\%) in Meru district in Tanzania. Kamala et al. (2016) reported that $20 \%$ of the respondents in Kilosa District of Tanzania had heard about aflatoxins. In addition, Marechera and Ndwiga (2014) reported that $93 \%$ of the farmers in lower eastern Kenya had heard of aflatoxins in their respective areas. Lee et al. (2017) reported that only $10.2 \%$ of the respondents from six provinces of Vietnam had heard of aflatoxins. Monyo et al. (2010) reported that $65 \%$ of groundnut farmers in Malawi were aware of aflatoxin. The disparity in awareness between this particular study and other reported studies may be attributed to several factors, including the nature of the study population. For example, in Kenya, the aflatoxicosis events that killed a number of people may have elevated the awareness of the public on aflatoxins (Probst et al. 2007). In Tanzania, the 2016 aflatoxicosis outbreak in the Dodoma region might have contributed to the increased awareness, more specifically to maize and groundnuts value chain actors. Training on food handling and storage helps to increase awareness on the best practices in the spice value chain, and hence might reduce the risks of aflatoxin contamination.

In this study, $16.7 \%$ of the respondents did not know the causes of spoilage of spices. This rate is higher than that reported by Marechera and Ndwiga (2014) in Kenya, where $4.2 \%$ of farmers in lower eastern Kenya did not know the cause of aflatoxin contamination in food crops. None of the respondents $(0.0 \%)$ in this study were aware of the effects of aflatoxins on quality of spices which is almost similar to what was reported by Ngoma et al. (2017). In that study only $1.4 \%$ of the respondents in central Tanzania were aware of the effects of aflatoxins. 
Table 8. Factors associated with aflatoxin contamination by characteristics of respondents.

\begin{tabular}{|c|c|c|c|c|c|}
\hline Variables & Category & $\begin{array}{l}\text { No. samples } \\
\text { analysed }^{1}\end{array}$ & $\begin{array}{l}\text { No. positive } \\
\text { samples }(\%)^{2}\end{array}$ & Chi square & $P$-value ${ }^{3}$ \\
\hline \multirow[t]{4}{*}{ Age (yrs) } & $18-26$ & 24 & $10(41.7)$ & 6.573 & 0.087 \\
\hline & $27-35$ & 48 & $29(60.4)$ & & \\
\hline & $36-44$ & 32 & $23(71.9)$ & & \\
\hline & 45 and above & 16 & $7(43.8)$ & & \\
\hline \multirow[t]{5}{*}{ Education level } & did not complete primary education & 4 & $4(100)$ & 14.08 & $0.007^{*}$ \\
\hline & completed primary education & 60 & $41(68.3)$ & & \\
\hline & did not complete ordinary level & 12 & $6(50.0)$ & & \\
\hline & completed ordinary level & 40 & $18(45.0)$ & & \\
\hline & post-secondary/tertiary & 4 & $0(0.0)$ & & \\
\hline \multirow[t]{3}{*}{ Where spices purchased } & farmers & 48 & $31(64.6)$ & 5.224 & 0.073 \\
\hline & outlets & 52 & $31(59.6)$ & & \\
\hline & others & 20 & $7(35.0)$ & & \\
\hline \multirow[t]{2}{*}{ Can identify spoiled spices } & no & 8 & $6(75.0)$ & 1.074 & 0.300 \\
\hline & yes & 112 & $63(56.2)$ & & \\
\hline \multirow[t]{2}{*}{ Know causes of spoilage in spices } & no & 20 & $14(70.0)$ & 1.535 & 0.215 \\
\hline & yes & 100 & $55(55.0)$ & & \\
\hline \multirow[t]{2}{*}{ Further drying of spices } & no & 76 & $40(52.6)$ & 2.010 & 0.156 \\
\hline & yes & 44 & $29(65.9)$ & & \\
\hline \multirow[t]{2}{*}{ Sorting of spices } & no & 28 & $20(71.4)$ & 2.899 & 0.089 \\
\hline & yes & 92 & $49(53.3)$ & & \\
\hline \multirow[t]{3}{*}{ Criteria for sorting spices } & no sorting done & 28 & $20(71.4)$ & 2.905 & 0.234 \\
\hline & physical aspects & 56 & $30(53.6)$ & & \\
\hline & insect and/or mould infestation & 36 & $19(52.8)$ & & \\
\hline \multirow[t]{3}{*}{ Storage length of spices (days) } & within 7 days & 76 & $42(55.3)$ & 1.680 & 0.432 \\
\hline & 7-14 days & 32 & $18(56.2)$ & & \\
\hline & more $>14$ days & 12 & $9(75.0)$ & & \\
\hline \multirow{2}{*}{$\begin{array}{l}\text { Attended any training on } \\
\text { food handling \& storage }\end{array}$} & no & 116 & $69(59.5)$ & 5.598 & $0.018^{*}$ \\
\hline & yes & 4 & $0(0.0)$ & & \\
\hline
\end{tabular}

About $94.9 \%$ of the respondents in the study reported by Jolly et al. (2006) did not know that aflatoxins caused illhealth effects. Furthermore, 93.3\% of the respondents in this study were able to identify spoiled spices, which is similar to a study done by Ayo et al. (2018), who reported that $93 \%$ of the livestock farmers in Meru district could identify mouldy feeds. Being able to identify spoiled spices may be attributed by the fact that these respondents were looking at physical aspects of the product in terms of appearance, but may not associate it with safety aspects, such as aflatoxin contamination. This is supported by the fact that $56.2 \%$ (Table 6) of retailers who could identify spoiled spices had contaminated spices. This is an indication of low awareness on post-harvest management to reduce aflatoxin contamination. However, our study showed higher percentage than the study by Marechera et al. (2014), who reported that $81.7 \%$. of participants could identify fungal growth or symptoms associated with aflatoxin contamination.

\section{Association between respondents' characteristics/ practices and aflatoxin contamination of spices}

The results of this study show that aflatoxin contamination of spices collected from respondents was significantly associated with age of the spice retailers. Traders aged between 36 and 44 years old were more likely to have contaminated spices compared to their younger and older peers, even though the odds of this were weak/low. This could be due to the fact that younger groups were more likely to be better educated or informed. Ayo et al. (2018) and Lee et al. (2017) reported that younger age groups were 
more aware of aflatoxins and had the ability and curiosity to learn. This is reflected by the respondents who attended training and were aged between 18 and 26 years. Hence, they were more likely to be aware of methods of preventing spoilage and aflatoxin contamination or able to seek further information.

This study revealed that the spices purchased from farmers and the storage duration were significantly associated with aflatoxin contamination. It was observed that spices bought from farmers were likely (but at lower odds) to be contaminated with aflatoxins compared to those purchased from retail outlets, or originating from other sources, such as own production. This might be due to poor post-harvest management by farmers. Most of the farmers dry the spices on the ground which may cause an increase in water activity of the spices due to absorption of moisture from the soil and re-wetting by rain which may lead to growth of mould hence aflatoxin contamination (Kaaya and Kyamuhangire, 2006). Also, most farmers do not apply physical sorting, which is an effective method to reduce aflatoxin contamination (Bullerman and Bianchini, 2007).

\section{Conclusions and recommendations}

This study provides a preliminary insight into aflatoxin contamination in spices marketed in Tanzania, as well as to the awareness, knowledge and handling practices associated with aflatoxin contamination in this country. It showed that prevalence of aflatoxins in marketed spices within Dar es Salaam is as high as $57.5 \%$ and there is an extremely low (3.3\%) awareness on aflatoxins among spice retailers in the region.

The study confirmed that unless measures are taken to raise awareness and knowledge about the ill-health effects of aflatoxins on human and animals, key players and parties engaged in the spice value chain may not take the necessary initiatives to prevent future contamination in the sector.

Thus, interventions based on regulatory and educational programmes on good management practices, as well as continuous surveillance and monitoring should be extended to producers and distributors of spices in order to protect the general public against dietary exposure to aflatoxins and promote safe trade of this commodity.

This is the first study of aflatoxins in spices from Tanzania. The presence of aflatoxins in spices is indicative of the possible presence of other mycotoxins, such as ochratoxin A which has been identified as a co-contaminant with aflatoxins in spices from other countries. Further studies focussed on the co-occurrence of other mycotoxins in spices marketed in Tanzania are recommended.

\section{Acknowledgements}

The authors would like to thank Dr. Arnau Vidal and Dr. Marthe De Boevre for their valuable input in this article. This research was funded by the Tanzania Bureau of Standards.

\section{Conflict of interest}

The authors declare no conflict of interest.

\section{References}

Adekoya, I., Njobeh, P., Obadina, A., Chilaka, C., Okoth, S., De Boevre, M. and De Saeger, S., 2017. Awareness and prevalence of mycotoxin contamination in selected Nigerian fermented foods. Toxins 9: 363.

Arapcheska, M., Jovanovska, V., Jankuloski, Z., Hajruali-Musliu, Z. and Uzunov, R., 2015. Impact of aflatoxins on animal and human health. International Journal of Innovative Science Engineering and Technology 2: 2348-7968.

Asghar, M.A., Zahir, E., Rantilal, S., Ahmed, A. and Iqbal, J., 2016. Aflatoxins in composite spices collected from local markets of Karachi, Pakistan. Food Additive and Contaminants Part B 9: 113119.

Ayo, E.M., Matemu, A., Laswai, G.H. and Kimanya, M.E., 2012. Socioeconomic characteristics influencing level of awareness of aflatoxin contamination of feeds among livestock farmers in Meru district of Tanzania. Scientifica 2012: 3485967.

Bryden, W.L., 2007. Mycotoxin contamination of the feed supply chain: implications for animal productivity and feed security. Animal Feed Science and Technology 173: 134-158.

Bullerman, L.B. and Bianchini, A., 2007. Stability of mycotoxins during food processing. International Journal of Food Microbiology 119: 140-146.

Cammilleri, G., Graci, S., Collura, R., Buscemi, M.D., Vella, A., Macaluso, A., Giaccone, V., Giangrosso, G., Cicero, A., Lo Dico, G.M., Pulvirenti, A., Cicero, N. and Ferrantelli, V., 2019. Aflatoxin $\mathrm{M}_{1}$ in cow, sheep and donkey milk produced in Sicily, Southern Italy. Mycotoxin Research 35: 47-53.

Filazi, A. and Sireli, U.T., 2013. Occurrence of aflatoxins in food. In: Razzaghi-abyaneh, M. (ed.) Aflatoxins - recent advances and future. InTech, Rijeka, Croatia, pp. 153-407.

International Agency for Research on Cancer (IARC), 2002. Aflatoxins. Monograph on the evaluation of carcinogenic risks to humans. IARC, Lyon, France, pp. 171.

Iqbal, Q., Amjad, M., Asi, M.R. and Ariño, A., 2012. Mold and aflatoxin reduction by gamma radiation of packed hot peppers and their evolution during storage. Journal of Food Protection 75: 1528-1531.

Ismaiel, A.A. and Papenbrock, J., 2015. Mycotoxins: producing fungi and mechanisms of phytotoxicity. Agriculture 5: 492-537.

Jolly, P., Jiang, Y., Ellis, W., Awuah, R., Nnedu, O., Phillip, T., Wang, J., Afriyie-Gyawu, E., Tang, L., Person, S., Williams, J. and Jolly, C., 2006. Determinants of aflatoxin levels in Ghanaians: socio demographic factors, knowledge of aflatoxin and food handling and consumption practices. International Journal of Hygiene and Environmental Health 209: 345-358. 
Kaaya, A.N. and Kyamuhangire, W., 2006. The effect of storage time and climatic zone on mould incidence and aflatoxin contamination of maize from traders in Uganda. International Journal of Food Microbiology 110: 217-223.

Kamala, A., Shirima, C., Jani, B., Bakari, M., Sillo, H., Rusibamayila, N., De Saeger, S., Kimanya, M., Gong, Y.Y., Simba, A. and the investigation team, 2018. Outbreak of an acute aflatoxicosis in Tanzania during 2016. World Mycotoxin Journal 11: 311-320.

Kamala, A., Kimanya, M., Haesaert, G., Tiisekwa, B., Madege, R., Degraeve, S., Cyprian, C. and De Meulenaer, B., 2016. Local post-harvest practices associated with aflatoxin and fumonisin contamination of maize in three agro-ecological zones of Tanzania. Food Additives and Contaminants Part A 33: 551-559.

Kothari, C.R and Garg, G., 2014. Research methodology (methods and techniques), $3^{\text {rd }}$ edition. New Age International Publishers, New Delhi, India.

Lee, H.S., Nguyen-Viet, H., Lindahl, J., Thanh, H.M., Khanh, T.N., Hien, L.T.T. and Grace, D.A., 2017. Survey of aflatoxin $B_{1}$ in maize and awareness of aflatoxins in Vietnam. World Mycotoxin Journal 10: 195-202.

Lewis, L., Onsongo, M., Njapau, H., Schurz-Rogers, H., Luber, G., Kieszak, S. and Rubin, C., 2005. Aflatoxin contamination of commercial maize products during an outbreak of acute aflatoxicosis in eastern and central Kenya. Environmental Health Perspectives 113: 1763-1767.

Lippolis, V., Irurhe, O., Porricelli, A.C.R., Cortese, M., Schena, R., Imafidon, T., Oluwadun, A. and Pascale, M., 2017. Natural cooccurrence of aflatoxins and ochratoxin A in ginger (Zingiber officinale) from Nigeria. Food Control 70: 1061-1067.

Lutfullah, G. and Hussain, A., 2012. Studies on contamination level of aflatoxins in some cereals and beans of Pakistan. Food Control 23: 32-36.

Magembe, K.S., Mwatawala, M.W., Mamiro, D.P. and Chingonikaya, E.E., 2017. Assessment of awareness of mycotoxins infections in stored maize (Zea mays L.) and groundnut (Arachishypogaea L.) in Kilosa District, Tanzania. International Journal of Food Contamination 3: 12.

Makun, H.A., Dutton, M.F., Njobeh, P.B., Mwanza, M. and Kabiru, A.Y., 2011. Natural multi-occurrence of mycotoxins in rice from Niger State, Nigeria. Mycotoxin Research 27: 97-104.

Marechera, G. and Ndwiga, J., 2014. Farmer perceptions of aflatoxin management strategies in lower eastern Kenya. Journal of Agriculture Extension and Rural Development 6: 382-392.
Marin, S., Ramos, A.J., Cano-Sancho, G. and Sanchis, V., 2013. Mycotoxins: occurrence, toxicology, and exposure assessment. Food Chemistry Toxicology 60: 218-237.

Monyo, E.S., Walliyar, F., Osiru, M., Siambi, M. and Chinyamumyamu, B., 2010. Assessing the occurrence and distribution of aflatoxins in Malawi. Project final report. ICRISAT, Lilongwe, Malawi. Available at: http://oar.icrisat.org/7380/1/Aflatoxins.pdf.

Ngoma, S.J., Kimanya, M. and Tiisekwa, B., 2017. Perception and attitude of parents towards aflatoxins contamination in complementary foods and its management in central Tanzania, Journal of Middle East and North Africa Sciences 3: 6-21.

Omar, H.E.M., 2013. Mycotoxins induced oxidative stress and diseases. In: Makun, H.A. (ed.) Mycotoxin and food safety in developing countries. InTech, Rijeka, Croatia, pp. 75-104.

Probst, C., Njapau, H. and Cotty, P.J., 2007. Outbreak of an acute aflatoxicosis in Kenya in 2004: identification of the causal agent. Applied and Environmental Microbiology 73: 2762-2764.

Reddy, K.R.N., Salleh, B., Saad, B., Abbas, H.K., Abel, C.A. and Shier, W.T., 2010. An overview of mycotoxin contamination in foods and its implications for human health. Toxin Review 29: 16-39.

Sasamalo, M.M., Mugula, J.K. and Nyangi, C.J., 2018. Aflatoxins contamination of maize at harvest and during storage in Dodoma, Tanzania. International Journal of Innovative Research and Development 7: 11-15.

Shah, V.P., Midha, K.K., Findlay, J.W., Hill, H.M., Hulse, J.D. and McGilvary, I.J., 2000. Bioanalytical method validation. A revisit with a decade of progress. Pharmaceutical Research 17: 1551-1557.

Thanushree, M.P., Sailendri, D., Yoha, K.S., Moses, J.A. and Anandharamakrishnan, C., 2019. Mycotoxin contamination in food: an exposition on spices. Trends in Food Science and Technology 93: 69-80.

Tosun, H. and Arslan, R., 2013. Determination of aflatoxin b1 levels in organic spices and herbs. Scientific World Journal 2013: 874093.

Unnevehr, L. and Grace, D., 2013. Aflatoxins: finding solution for improved food safety. 2020 vision focus. International Food Policy Research Institute, Washington, DC, USA.

World Health Organisation (WHO), 2006. Global environment monitoring system - food contamination monitoring and assessment programme. WHO, Geneva, Switzerland.

World Health Organisation (WHO), 2017. Weekly bulletin on outbreaks and other emergencies. WHO, Geneva, Switzerland. 